\title{
Using Technology and Instructional E-Material among Technical Teacher and Student into Teaching and Learning: A Qualitative Case Study
}

\author{
Mohamad Hisyam Mohd. Hashim ${ }^{1}$ \\ ${ }^{1}$ Faculty of Technical and Vocational Education, Universiti Tun Hussein Onn Malaysia (UTHM), Malaysia \\ Correspondence: Mohamad Hisyam Mohd. Hashim, Faculty of Technical and Vocational Education, Universiti \\ Tun Hussein Onn Malaysia (UTHM), Malaysia. Tel: 601-3777-0161. E-mail: mhisyam@uthm.edu.my
}

Received: October 24, 2014 Accepted: November 30, 2014 Online Published: February 26, 2015

doi: $10.5539 /$ ies.v8n3p 175

URL: http://dx.doi.org/10.5539/ies.v8n3p175

\begin{abstract}
The development of instructional electronic material or e-material for electrical and electronic studies was developed by many companies and institutions. However, the quality of the designed and the potentiality to use as a tool in teaching and learning is still doubtful. For this reason, the aim of this research was to understand the using technology and Instructional E-Material among technical teacher and student into teaching and learning. A qualitative case study methodology had been used to collect and analysis the data rigorously through several activities of interview, analysis of documentation and observation by researchers. The research was done at two established technical schools in Malaysia which involved some students and teachers in the schools. The finding shows that using technology into teaching and learning was preferred by technical teachers and students and e-material as a tool which will be enhanced to understand the subject of electrical and electronic as well. Assuredly, the teachers have masterly integrated in the e-material with their process of teaching and the students have to properly integrate into their learning process.
\end{abstract}

Keywords: e-material, teacher, student, content, instructional

\section{Introduction}

The development of technology was seen very magnificent change in the world of education. Most variety of teaching aids, eventually, it has assisted teachers in assuring the smoothness of teaching and learning process to take place in classes. The use of technology in education is as important as other teaching aid tools in class, in order to facilitate and develop the students' understanding pertaining to certain topic which has been taught in class. The E-module is one of the most worthwhile computing technologies which had been used widely. It has been used for learning to takes place to be either in electronic or digital ways. The use of e-module is believed to enhance understanding of the subject. By mastering the knowledge and hard skills in electrical and electronic field, with the molded attitude and outstanding value of work, students will be able to succeed as well. However, to ensure the process of learning and teaching are smooth, the teacher has to analysis the E-module. The analysis is believed to guarantee that the students will achieve knowledge and skills of electric and electronic.

The teacher is a role model in educating and nurturing the students with the knowledge. The concept of teaching which has been used by the teachers should be aligning with activities and the objective which need to achieve. They are many kinds of teaching tools can be used by teachers to support the process of teaching. By using the teaching aids, teachers are able to make the teaching process becomes more energetic, interesting and comprehensible. However, with the condition that the contents should be more precise and are close to the related topic. Hence, the teachers should be alert in choosing the effective methods of teaching. It helps the process of teaching and learning smoothly. This paper will be answered the question of how the technical teacher and student using technology and instructional e-material in teaching and learning?

\section{Literature Review}

The momentum growth of ICT is capable enough to play the role of aiding the main activity of educating which is the development of the learning module, delivery of teaching, learning and evaluation strengthening program (Hassan et al., 2000). The Curriculum developers will be the one who decide the rationale, structure, philosophy, content, value and purpose of the curriculum, whereas the instructional includes technology expertise are looking 
for the best way of teaching the curriculum contents to the students. In this context, according to Hashim (2000), the best way of teaching answers what strategy, methods and sorts of technology that is suitable to ease the process of learning the curriculum.

Keengwe and Anyanwy (2007) argue that teachers should understand the best and effective way for them in using technology in their teaching process, and the technology is focused to be a tool (acts to solve of problems by the students in learning science) for creating the process of learning more alive, concrete, interesting and entertaining. In this case, it is suggested that a module based on technology in teaching and learning science will give the opportunity for the students to explore the worth education.

Teachers are believed to get used to their teaching process to the concrete phase as possible as they can by relating the students' experiences in order to ease the process of shaping the concept into their learning (Razali, 2000). Needless to say, multimedia courseware conveys the lesson messages to the student successfully in easier form and more interesting than textbooks or other multimedia, and it is focused on fulfilling the various learning strategies (Ellis, 2004). Each individual has their own style of learning. Educating them traditionally will not solve the problem of ranges style of learning. Thereby, this devastated technology, computer, will give all the facilities for the students to learn.

Gagne (1985) claims that students should be able to do revision repeatedly. Most of them can fully comprehend the particular concept which has been taught in class. Pertaining to this matter, Mayer and Anderson (1992) assert that certain information which is passed on verbally, oral for instance, includes text which is not in the form of verbal, for examples; pictures, animation, and videos, are believed to enhance the capacity of memorizing and receive the related information from memory. Multimedia courseware has practically used this concept whereby texts and oral is combined on the screen with the same graphic, animation and video. The content of the course' syllabus should be analyzed based on the existed module like textbooks. This learning oriented courseware system is for the students who will be continued learning the course with their own pace and capability.

\section{Methodology}

A qualitative research methodology and case study strategy was used for collecting and analyzing information. The qualitative process was used to collect all information in the certain time and period. The data were collected from the interviewing session is hence fall onto the primary data in this study. Meanwhile, observing method, documents and data triangulation method are also performed to back up the existed primary data; interviewing data. In this study, the researcher is using the secondary data which are collected from journal, books, literature reviews and the internet. These sorts of data are used for adding the reading materials which will be used in this study and are believed to answer the questions of the conducted study.

Many qualitative researchers declare that interviewing is one of the methods that can be used by the researcher to explore the students' world and understand the real situation which faced by the students. Among the advantages of this method is the flexibility that one can have with someone who can explain certain ambiguous things. The strength of interviewing method is, it allows the researcher to get the response from individuals who are the participants of the study and the feedbacks are ranges from one to another in different situation. The main purpose of interviewing is to recognize the issues, process and situation to be analyzed. This study allows the researcher to use the structured interview methods. The structured interview method involves the rigid list of questions, where the researcher will be asking the participants the same type of questions with the same. This method is repeatedly used by the researchers who wish to get information in limited time for the long term. Hence, the researcher will firstly design the checklist about what items to be analyzed.

Some light on the aspect of observation by saying that the observing method gives a chance for the researchers to witness and see, hear and experience the real situation. With this method, the researcher will get the clear cut on how certain thing happen, what are the teaching methods applied by teachers, and how the teachers conduct the learning planning by using the presented learning environment. While observing a particular phenomenon, the situation (for instance the conversation among teachers in the teachers' room, interactions among students) or activity, (for example, teaching and learning progress in the classroom), is essential for the researcher to take immediate note. This note is known as field notes.

Generally, the analysis of the document is a breakdown of the research content analysis method which explains the objective upon the communication messages which have been printed, published or pictured. In other words, the part of the message can be heard, obtained, seen by the reference of the content of texts in its words, meanings, images, symbols, ideas, themes or anything which related to the communicated messages. It includes the activities of reading, reviewing, choosing and filtering the texts which have been recognized as materials or 
data for the research.

In ensuring the collected information in this qualitative research are precise and valid in the sense of its theory and also is reliable, proofs from the different sources are very important. Information which is obtained from particular source will be verified in accordance to the same issues from another source. The process of verifies the different sources is known as triangulation process. In this context of study, for verifying the information about the methods of teaching which are obtained by teachers who teach the form four students the subject of electrical and Electronic, the researchers will try to get the same information from different sources, for instance, the head of the committee, subject matter expert and from the teaching documents which have been prepared by the teachers for enhancing the verification of the given information. For the research which is conducted by qualitative method through interviewing, observing and documentation of the efforts of the researcher in collecting data as much as possible, the use of triangulation technique itself could strengthen the verification of the study. The use of triangulation technique (interviews, questionnaires, and observes) concurrently in the study should be conducted in the form of equivalent (where by criteria and constructed items are the same from the various instrument).

The verification in the qualitative research (the user interviews, observations and documentations as instruments) is not only focusing on the finding of the research but also for the whole research process. There is no fixed rule in constructing verification in quantitative research. In contrary, McCall and Simmons (1969) strongly affirm that quantitative research through the collection of data from interviews and observations are needed for verifying process to take place. Campbell (1955) suggests that in order to solve the problem of verification on the collected qualitative data, particularly the data from interviews, "morale ballot" technique should be applied. On the other hand, Bailey (1978) and Scoot (1961) propose the use of the independent rating technique through the cross-checking process to verify the qualitative data.

NVivo is a computer software program developed by Qualitative Solutions and Research International (QSR) since 1999. This software is designed to help qualitative researchers, especially those who need to work with text-based data and multimedia information (such as video, images, and pictures), where a deeper level of analysis can be performed on large amounts of data. NVivo software designed to manage and analyze qualitative data, which is data that is not structured, and complex non-numerical. This software allows users to classify and organize thousands of information collected, reviewed the complex relationships between the data, the combined analysis with linking, shaping and generating model. In short, NVivo 10 is a very effective tool and useful to manage, search, analyze, and generate theory. In this study, NVivo software will help researchers analyze the data collected.

\section{Finding and Discussion}

\subsection{Using Technology into Teaching in Technical Schools}

Many methods of teaching had been applied by teachers in technical school. However, they were not really confident about the method. The teachers were approaching the students to learn based on the contents of the texts books itself when they are not in the class. Actually, the teacher also had other sources being used such as an interactive compact disk (CD), certain WebPages and other reference books. They used more than one learning sources but they still delivering the subject as a conventional process. They are still using textbook as a main source in teaching. The textbook had been optimally used, might be because the book produced and published by the ministry.

\footnotetext{
"In teaching, I use the textbook as my main source. If students have confusion in a topic, I will ask them to refer to the textbook because teaching and learning are based on primary source, textbooks. So I will continue to emphasize to the students to use and refer to the text. Furthermore, if any of the test questions will be based on the textbook as well. I will also refer to other sources such as $\mathrm{CD}$, certain web sites, reference books etc. etc. to further enhance my knowledge" (Ahmad)
}

The teachers also used some documentation materials for teaching. The teachers had a few teaching aids where was used for teaching and learning in the classroom. The main teaching source was the textbook, but some teachers informed that they only used one material. The teachers should be using more vareaties of learning aids. A part from using textbook, for instance, the teacher also has referred to other sources like module and workbook which is compulsory used in their teaching. According the teachers, he would make sure that his students be the 
textbook as a main reference. All the situations were happening when they didn't have any electronic learning sources.

The use of only the textbook didn't not given the whole understanding to all the students, in fact it does not help the students to comprehend certain topic being taught in class. The teachers has chosen the module learning method to approach her students as for teachers, the material of P\&P should be easy, brief, concise and precise. Teachers believe that the teaching method through module is used to make the students understood from what has been taught in class, gives some benefits and easier to prepare. All in all, the learning module patterned is among the suitable approaches to be explored. He also informed that the use of modules is easier for him to make his students successfully comprehend the certain topic which listed in the textbook. This is because the content in the module provides notes and important issues exactly like in the textbook. These findings are based on his statement.

"I'm more comfortable using modules from other teaching methods or other teaching aids. For me, when the modules had been used, I present the lessons easier to understand by students. After the content of the module is similar to the content of textbooks, even have many advantages and are more easily available. Perhaps a way of organizing the module to more organized and more clearly". (Azlan)

Indeed, the textbook is still referred by the students whenever they could not cope with certain topics.

According to the others teacher, she used the teaching aids as a method of teaching. She had used interactive compact disk (CD) which will enable her to create the smooth process of teaching and learning. She said that the $\mathrm{CD}$ had eventually attracted the interest of her students to learn the subject, but his students were also given some questions for revision in the form of self-assessment which had included in the textbook. The self-assessment had been designed to evaluate the understanding of the students pertaining to the certain topics within in a certain period.

"I use an interactive CD as a teaching aid in my teaching. Now we're no better technology than ever before this. I will use the laptop provided by the government and I take my time teaching in the workshop as well. For me the use of this CD is not only to attract the attention of students, but students will better understand the subject matter is learned. Upon completion of the lesson for a topic, I will give them many exercises of the question. For me strengthening exercises provided in the textbook can real test students understanding level. In addition, I also asked them to answer the questions contained in the self-assessment textbooks as well" (Jamilah)

Thereby, the method had been used by her is believed to be able to her students understood the course very well. To strengthen the interviewed, researcher had analyzed some documents as a secondary source for the research. The findings from the document analysis shows that the content of the textbook for Electrical and Electronic Engineering Studies at form four enclose the various aspect of learning particularly from the aspect of questions for workout and practice, suggested practical workout, reminding corner, notes and additional information plus the corner which suggests the suitable WebPages related to the topic for the students to get the additional information and knowledge. In fact, there is strengthening workout, and not to forget there are also self-assessment and self assessment workout. As a conclusion, the methods of teaching applied by the participants are suitable and on the right track, following the curriculum syllabus for this subject. As overall, the participants were using the methods of module as their alternative methods in replacing the textbook while teaching.

\subsection{Using E-Module into Teaching and Learning}

The findings had shown that the participants of the study were encouraging the school administration used the latest technology to assist the teachers using the teaching aids. Some teachers, was also the participants had suggested in order to the schools could be enhance the development of the courseware technology. The development of high quality courseware could be used by the teachers and students and will be made the learning interesting and entertaining rather than other methods. A technical teacher said: 
"The school must keep abreast of current technology because it can diversify the teaching aids. And, invariably it is also able to diversify teaching methods or techniques. So, with this variety of teaching aids teachers can work together and strive in Electronics \& Electrical Engineering studies enhance the teaching of this subject"(Isla)

The school administration should be taken the wise option by moving into the usage of technology in the world of education. Moreover, the usage of technology in education should be created the diversity of existed teaching techniques and methods among the teachers. As a matter of fact, with the latest aiding teaching tools, the teachers could be collaborated with another for reinforcing their teaching methods for the subject. The technical teachers have to learn and competent for producing courseware for teaching and assist the students to understand as well.

Some participants have emphasized on the demonstration method which involved practical in the workshop should be shed some light on. The student has really accepted the situations and clear with the ways of things are conducted while the practical being practiced. I understand that the need for aspect of the demonstration and assimilation are important in helping the teachers soothing their teaching strategies. One of the participants deduces that the use of the self-assessment module is the most effective method for students to understand certain topics for this subject. She said.

"In my opinion the use of the self-assessment module is the most effective method to facilitate students' understanding of the topic of the subject. For me, this module can help to improve critical thinking among students. So indirectly when students were able to complete tasks in the module, students will be able to better understand a topic of study for that. Furthermore, with the availability of the module teachers can encourage the students to find their own information related to the topic being discussed" (Ramiah)

Ultimately, whenever the students comprehend the lessons and are able to solve the assessment, the students will enhance their level of understanding of the topic which has been learnt to the better level. In addition, with the usage of the module, the teachers are advised and encouraging the students to look for the additional information related to the topic which is being learnt.

Participants had also said that the use of interactive Compact Disk (CD) as a tool, was the best method which will be assisted the students to understand the topic was delivered by the teachers. It showed that with the usage of the $\mathrm{CD}$, the pictures and images, graphic and three-dimension form will up the skill of visualization among the students. The explanation of the topic by teachers will be more fantastic and dramatized by the naked eyes, the interactive $\mathrm{CD}$ would make the ambitious clearest and the students will face no more difficulty in imagining something. These findings were based on her words that:

\begin{abstract}
"My view on the most effective method is a method of teaching aids which use interactive CD. Because we can make the most effective method to facilitate students' understanding of difficult topics taught. The reason there is content on the $\mathrm{CD}$ is in the form of photographs and three-dimensional graphics. That's interesting. So through the use of the $\mathrm{CD}$ it can enhance student visualization skills. Furthermore, if the topic involves descriptions of teachers cannot be described by the naked eye, then with the advent of interactive CD to students will feel more fun and get a glimpse of the true picture as found on the CD" (Jasmin)
\end{abstract}

With the analysis of the document, generally the participants in this study were using a module and interactive $\mathrm{CD}$ in conveying their teaching strategies. The surroundings of the participants had made their exercise books and also practical reports which eventually make their surrounding loaded. The use of aiding teaching tools as teaching and learning materials should give the curriculum developer spaces and times for them to find another option in producing the high quality materials of T\&L which as pure as other developed country not to forget by using the contents of the existed textbooks. The finding of the study shows that the school should necessarily take a new approach to ensure a variety of reference sources for the students to learn the subject.

\title{
5. Conclusions
}

A research about Using Technology and Instructional E-Material among Technical Teacher and Student in 
Teaching and Learning had been done. Unfortunately, in technical education, especially in technical schools, they don't have expertise in developing the e-material. However, they used technology as tools into teaching and learning. The Compact Disk (CD), e-book, laptop and internet was used frequently by the technical teacher. Teachers who interested in developing an e-material should be given opportunities to attend some courses on how to develop the e-material. The process of development of e-instructional material should be introduced in technical school. Many researches on e-module need to be done for improving the quality and teaching methods. It is important to ensure that culture of learning will be enhanced the quality of education system in the country especially to technical teachers. However, not many people understand clearly the application of technology to support the learning process. In reality, they need to realize that the technology changed every day. Hence, technical teachers should always be ready to change and should be prepared to face every reform to be introduced in line with the national vision that wants to make Malaysia to be a developed country by the year 2020.

\section{References}

Bailey, K. D. (1978). Methods of Social Research. New York: The Free Press.

Campbell, D. (1955). The Informant in Quantitative Research. American Journal of Sociology, 60, 339-342. http://dx.doi.org/10.1086/221565

Ellis, R. (2004). The Definition and Measurement of Explicit Knowledge. Language Learning, 54, 227-275. http://dx.doi.org/10.1111/j.1467-9922.2004.00255.x

Gagne, R. (1985). The Conditions of Learning and the Theory of Instruction (4th ed.). New York: Holt, Rinehart, and Winston.

Hashim, Y. (2000). Concept and Development of Curriculum and Instruction. Kuala Lumpur: Utusan Publication.

Hassan, M. N. et al. (2000). Research and E-Learning Development at UTM. Paper Presented.

Keengwe, J., \& Anyanwu, L. (2007). Computer technology-infused learning enhancement. Journal Science Educational Technology, 16(5), 387-393. http://dx.doi.org/10.1007/s10956-007-9067-1

Mayer, R. E., \& Anderson, R. B. (1992). Animations need narrations: An experimental test of dual-coding hypothesis. Journal of Educational Psychology, 83, 484-490. http://dx.doi.org/10.1037/0022-0663.83.4.484

Mc Call, G. J., \& Simmons, J. L. (1969). Issues in Participant Observation: A Text and Reader. Reading Mass: Addison-Wesley Pub. Co.

Razali, S. N. (2000). Data Analysis in Education Research. Kuala Lumpur: Dewan Bahasa and Pustaka.

Scoott, C. (1961). Research on Mail Survey. Journal of the Statistical Society, 24, 12.

\section{Copyrights}

Copyright for this article is retained by the author(s), with first publication rights granted to the journal.

This is an open-access article distributed under the terms and conditions of the Creative Commons Attribution license (http://creativecommons.org/licenses/by/3.0/). 